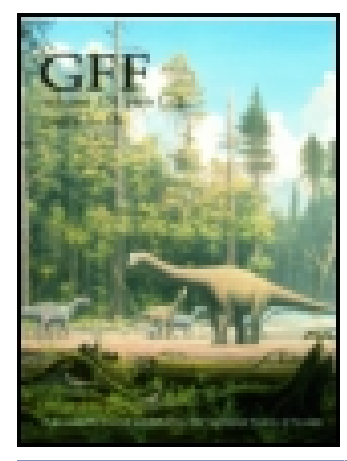

Geologiska Föreningen i Stockholm Förhandlingar

\title{
Undersökning af postglacial lera ("svartlera") från Göteborg
}

\author{
J. E. Alén
}

To cite this article: J. E. Alén (1888) Undersökning af postglacial lera ("svartlera") från Göteborg, Geologiska Föreningen i Stockholm Förhandlingar, 10:5, 341-344, DOI: $\underline{10.1080 / 11035898809444213}$

To link to this article: http://dx.doi.org/10.1080/11035898809444213

曲 Published online: 06 Jan 2010.

Submit your article to this journal $\square$

Џ Article views: 8

Q View related articles $\square$ 
GEOL. FöneN. FönHANdL. N:o 117. Bd X. . Häft. 5.341

\section{Undersökning af postglacial lera ("svartlera") från Göteborg.}

if

J. E. ALÉN.

De prof af postglacial lera frản Göteborg, som undersükts, lafia tagits på trenne ställen: a) på cirka 7 fots djup nära liürnct af Drottning- och Vestra Hanngatorna under pågående gräfning för grundlïggning af bolaget Sreas hus; $b$ ) på cirka 15 fots djup a -samma stïlle som $a$ ); $c$ ) på ungefär $11 \frac{1}{2}$ fots djup i exercisheden nïra Katrinetorp under der pågående gräfning för lygggande af en kulvert. Enligt uppgift skall på fürstnämda ställe fast häll påtrïffas på 30 ì 45 fots djup.

Leran a) var till färgen blåaktigt grå, mörkflammig eller mörkrandad, till konsistensen ganska lös, innehållande här och der vïxtrester. På en del ställen syntes tydligt, huru leran genomträngdes af små cylindriska, rostfärgade partier (roströr), som voro grupperade kring en dylik leran genomsättande växtrest, som även ibland syntes helt och hallet hafva försvunnit, lemnande efter sig ett litet, ett par millimeter vidt hail.

Den djupare liggande leran $b$ ). liknade den nyssnämda leran; dess mörkflammighet var dock mindre tydlig ${ }^{1}$ ). Den innehöll ocksa växtrester, kring hvilka dock inga roströr syntes hafva bildats. MIusselskal skola emellanåt rid grïfningarna påträffas; jag iakttog blott ett enda litet sidlant, som var krossadt, uti leran $b$ ).

3) Deuna mörkflammighet bos leran kan möjligen bero på förorening från den gamla byggoadsgrunden; men sannolikare är räl dock, att den är mera ursprunglig. 
Profvet frain Exercisheden, c), utgjordes af en blâatigt gri (ej märkbart mürkflammig) lera, innehaillande sand- och gruskorn, en och annan småsten samt små musselskal och växtreșter. I den till konsistensen lüsa leran funnos små hårdare lerklumpar (marlekeartade bildningar), hraribland en del roro tỵdligt genomborrade af ett hål, ett par millimeter vidt, lirari antagligen förut förefunnits någon växtrest. I lera, uppkastad invid kulrerten och härstammande från lager strax ofvan det, der prof $c$ ) togs, syntes det förekomma gansha mychet musselskal 1) samt växtrester; der förekommo ock stenar af mera betydande storlek.

Alla tre lerprofien fräste ganska starkt för saltsyra och utrecklade dervid tydlig lukt af stafvelväte.

\section{Mekanisk analys af lufttorkade mof:}

$$
\begin{aligned}
& \text { Lern och slamfin sand... } 88,78 \% \quad 89,51 \% \quad 88,21 \% \\
& \text { Sand mindre äu } 0,3 \mathrm{~mm} \quad 11,15 \Rightarrow 10,42 \text { " } 11,09 \text { " } \\
& \text { " } 0,5-1 \mathrm{~mm} . . . . . .0 .0,03 " \quad 0,00 " \quad 0.10 " \text { Grus } 1-1,5 \mathrm{~mm} \ldots . .0,10 \\
& \text { Grus stōrre än } 1 \text { nmm. } \\
& \frac{0,04}{100,00} \frac{0,01 n}{100,00} \frac{0,60 n}{100,00} \mid " \text { större än } 2 \text { mm } \frac{0,40}{0,60 .}
\end{aligned}
$$

Profven a) och $b$ ) likna sáledes hrarandra mycket till mekanisk sammansïttning; prof c) skiljer sig frain dem genom en väsendtlig lögre grushalt.

Slamningen rerkstäldes blott med tillijelp af en tubulerad bägare.

Bland den gröfre sanden och gruset ingingo partiklar af tydligt organiskt ursprung.

Blott profien $a$ ) och $b$ ) underkastades kemisk analys. Resultatet af den kemiska undersökningen är följande 3):

1) Sytilus, Synopsis undulata m. fl.

2) Stōrre delen af de kemiskt analy̆tiska bestāmningarna äro rerkstälda af in. geniör Birger Cha rueville. 


\begin{tabular}{|c|c|c|c|c|c|c|}
\hline & \multicolumn{2}{|c|}{$\begin{array}{l}\text { Lufttorkad } \\
\text { substans. }\end{array}$} & \multicolumn{2}{|c|}{$\begin{array}{c}\text { Berāknadt pả rid } \\
100^{\circ} \text { C. torkad } \\
\text { substans. }\end{array}$} & \multicolumn{2}{|c|}{$\begin{array}{c}\text { Beräknadt pa ur- } \\
\text { spronglig, fuktig } \\
\text { substans. }\end{array}$} \\
\hline & a) & b) & a) & b) & a) & b) \\
\hline Hygroskopiskt ratten $\left.{ }^{2}\right) .$. & $4,33 \%$ & $4,43 \%$ & - & - & $37,23 \%$ & $42,06 \%$ \\
\hline Kemiskt bundet ratten ${ }^{2}$ ) & $0,78 \cdots$ & 0,54 & $0,31 q$ & $0,57 \%$ & $0,50 \cdots$ & $0,33 \cdots$ \\
\hline $\begin{array}{l}\text { Organisk substang (beräk- } \\
\left.\text { nad som cellulosa) }{ }^{3}\right) \text {. }\end{array}$ & $0,73 "$ & $1.15 \mathrm{~m}$ & $0,76 n$ & $1,20 N$ & $0,48 \quad$ & 0,70 \\
\hline Kigelsyra...... & $53,20 "$ & 53,04 & $5 \overline{5}, 60 n$ & $55,50 \cdots$ & 34,90 " & $32,16 n$ \\
\hline Lerjord....... & $15,75 \mathrm{~m}$ & 16,38 & 16,46 & 17,13 & 10,33 & 9,93 ॥ \\
\hline Jernorid ........... & $6,94 ”$ & $7,22 》$ & $7,25 n$ & $7,55 \times$ & $4,55 \quad \cdots$ & $4,37 \quad "$ \\
\hline Magganorid ........ & . $s$ & a $\mathrm{a}$ & $01 \mathrm{i}$ & $k \quad t$ & $s \quad p \quad z$ & $\boldsymbol{r}$ \\
\hline Kolsyrad kalk ().... & $6,61 \triangleright$ & $4,82 \cdots$ & $6,90 "$ & 5,04 & $4,33 \cdot n$ & $2,92 \quad$ \\
\hline Kalk (i andan form) .... & $1,34 \cup$ & $1,58 \mathrm{n}$ & $1,40 n$ & $1,65 \cdots$ & 0,87 & 0,96 \\
\hline Magnesia . & $2,84 n$ & $2,75 \mathrm{w}$ & $2,96 n$ & $2,88 n$ & $1,35 \quad \cdots$ & $1,67 \%$ \\
\hline Natron .... & $2,50 \mathrm{~N}$ & $2,54 n$ & $2,61 n$ & $2,66 \mathrm{~N}$ & $1,63 \%$ & 1,54 " \\
\hline Kali .... & $4,60 \mathrm{~N}$ & 4,200 & $4,80 \cdots$ & 4,40 & 3,01 " & 2,55 \\
\hline Fosforsyra ............... & $0,23 n$ & $0,24 n$ & $0, \geq 4 n$ & $0,25 \cdots$ & $0,15 \cdots$ & $0,15 n$ \\
\hline Svafrelsyra ............. & $1,17 n$ & 0,91 & $1,22 "$ & $0,96 \times$ & $0,76 "$ & 0,56 \\
\hline Klor. & $0,11 n$ & 0,10 & $0,12 n$ & 0,11 & 0,07 & $0,0 \dot{h}^{\circ}$ \\
\hline Svafrel (i sulfuret) ... & - & - & i- & - & 0,007 & $0,005 "$ \\
\hline Summa & 101,13 & 99,90 & 101,13 & 99,90 & 100,667 & $\mid 99,965$ \\
\hline
\end{tabular}

Det är sâledes icke heller i kemiskt hänseende någon väsentlig skilnad mellan lerorna $a$ ) och b). Báda synas vara ovanligt rika på alkalier, i synnerhet kali.

För undersökning af leromas genomsläpplighet för vatten har jag, efter att lıafva pröfvat åtskilliga mindre säkra metoder, förfarit silunda:

i ett glasrör af $11-13 \mathrm{~mm}$ inre vidd instoppades leran, hrarvid icke kunde undrikas, det átskilliga luftblísor inneslötos i henne. Iueran hoppressades sedan derigenom att en kork in-

1) Genom torkning rid $100-110^{\circ} \mathrm{C}$.

${ }^{2}$ ) = Total glōdgningsförlust (fnnnen rid elementaranalys, hrarrid substansen fōrbrändes i skepp uti sgrgas) - (hygroskopiskt ratten + kolsyra + ucellolosan).

3) Frản den vid elementaranalgs fanas totala kolsỵrehalten frảndrogs den kolsyra, som utdrifres af syror. Resten koloyra, motsrarande organiskt bol, har beräknats som celluloss.

4) All rerklig kolşzra har berāknats som kolsygrad kalk. 
sattes $i$ rörets nedre ända och leran ofvanifrån hopstampades medelst en tjock glasstaf; för att förekomma lerans uppträngande på sidorna om glasstafven var en bomullstapp inskjuten, hvilken sedan utdrogs med ett snöre, som var lindadt kring bomullen. För att hindra leran att genom vattnets tryck glida ut ur röret, lindades kring dess nedre ända en tygbit. Ofvanpå leran göts sedan vatten till ett bestämdt märke. För att förebygga afdunstning af vatten fastbands nedtill ett profrör, innellållande litet vatten, och upptill slüts röret med en kork, försedd med ett glasrör, som var utdraget till ett fint kapillärrör. Glasröret upphängdes sedan, och efter naigon viss tid aflästes, hur mycket vattenpelaren minskat $\mathrm{i}$ längd, hvarefter vatten åter påfyldes till märket o. s. v. Sålunda hafva följande siffror erhållits:

\begin{tabular}{|c|c|c|c|c|c|c|c|c|c|c|c|}
\hline \multirow{2}{*}{ 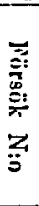 } & \multirow{2}{*}{ 离 } & \multirow{2}{*}{ 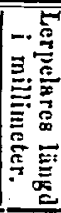 } & \multirow{2}{*}{ 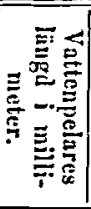 } & \multirow{2}{*}{ 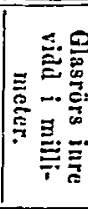 } & \multirow{2}{*}{ 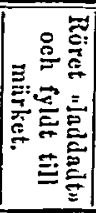 } & \multicolumn{6}{|c|}{ Vattenpelaren minskat $i$ längd millimeter } \\
\hline & & & & & & $11 / 118 \pi$ & 1111287 & $12 / 188$ & $11 / 288$ & $2 / 488$ & $2 / 868$ \\
\hline 1 & a) & 203 & 700 & 12 & $31 / 1287$ & - & - & 0 & 2 & 14 & 12 \\
\hline 2 & a) & 96 & 800 & 12 & $n$ & - & - & 4 & 12 & 31 & 33 \\
\hline 3 & a) & 58 & 140 & 12 & ه & - & 一 & 1 & 4 & 13 & 9 \\
\hline 4 & b) & 447 & 512 & 12 & $2 / 1187$ & 0 & 3 & 3 & 2 & 7 & 7 \\
\hline$\overline{\mathbf{5}}$ & b) & 115 & 830 & 11 & ${ }^{20} / 1287$ & - & - & 5 & 9 & 20 & 19 \\
\hline 6 & b) & 45 & 115 & 12 & v & - & - & 6 & 12 & 28 & 24 \\
\hline 7 & c) & 195 & 700 & 12 & . & - & - & 1 & 5 & 10 & $\mathrm{~s}$ \\
\hline 8 & c) & 112 & 640 & 11 & $"$ & - & - & 4 & 8 & 17 & 13 \\
\hline 9 & c) & $4 j$ & 100 & 13 & D & - & - & 2 & 5 & 13 & 71 \\
\hline
\end{tabular}

Ett störe eller mindre antal tvärgående springor hade småningom uppstått $\mathrm{i}$ leran.

Dessa försök visa, att alla profven äro föga genomsläppliga für vatten. I fürsük 1 och + syntes de t. o. m. icke alls vara genomsläppliga till, en bürjan. I naturen tränger troligen vattnet icke alls ned i dessa leror, för så vidt icke några springor föreflnnas, hvarigenom det kan nedtränga, eller vattnet möjligen tillfälligtvis innehåller några ämnen, som kemiskt angripa lerans beståndsdelar. Om vattnet t. ex. är surt, kan det lösa upp de kolsyrade salterna och i och med det samma intränga i leran. 